\title{
Failure to confirm influence of Methyltetrahydrofolate reductase (MTHFR) polymorphisms on age at onset of Huntington disease
}

\author{
Wiebke Hansen ${ }^{1}$, Carsten Saft ${ }^{2}$, Jürgen Andrich², Thomas Müller ${ }^{2}$, \\ Stefan Wieczorek ${ }^{1}$, Jörg T Epplen ${ }^{1}$ and Larissa Arning ${ }^{* 1}$
}

Address: ${ }^{1}$ Department of Human Genetics, Ruhr-University, 44780 Bochum, Germany and 2Department of Neurology, St. Josef-Hospital, RuhrUniversity, 44791 Bochum, Germany

Email: Wiebke Hansen - wiebke.hansen@rub.de; Carsten Saft - carsten.saft@cityweb.de; Jürgen Andrich - juergen.andrich@rub.de; Thomas Müller - thomas.mueller@rub.de; Stefan Wieczorek - stefan.wieczorek@rub.de; Jörg T Epplen - joerg.t.epplen@rub.de; Larissa Arning* - larissa.arning@rub.de

* Corresponding author

Published: 22 December 2005

Journal of Negative Results in BioMedicine 2005, 4:12 doi:10.1 I86/1477-575I-4-12

This article is available from: http://www.jnrbm.com/content/4/I/12

(C) 2005 Hansen et al; licensee BioMed Central Ltd.

This is an Open Access article distributed under the terms of the Creative Commons Attribution License (http://creativecommons.org/licenses/by/2.0), which permits unrestricted use, distribution, and reproduction in any medium, provided the original work is properly cited.

\begin{abstract}
Background: Huntington disease (HD) is a fully penetrant, autosomal dominantly inherited disorder associated with abnormal expansions of a stretch of perfect CAG repeats in the $5^{\prime}$ part of the ITI5 gene. The number of repeat units is highly predictive for the age at onset (AO) of the disorder. But $A O$ is only modestly correlated with repeat length when intermediate HD expansions are considered. Recently, suggestive association has been reported between a single nucleotide polymorphism (SNP; rs I 80 I I I , also known as A I298C) in the methyltetrahydrofolate reductase (MTHFR) gene and AO of HD. 5, I0-MTHFR is a key enzyme in the folate metabolism, diverting metabolites toward methylation reactions or nucleotide synthesis. Using part of a previously established study cohort plus additional patients and appropriate statistical methods, we reinvestigated two polymorphisms in the MTHFR gene, C677T and A/298C, as well as their association with $\mathrm{AO}$ in $167 \mathrm{HD}$ patients.
\end{abstract}

Results: There was no statistically significant impact on AO for HD patients, neither of MTHFR SNPs nor of the combinations thereof.

Conclusion: Contrary to previously described evidence the AI298C polymorphism in the MTHFR gene does not appear to modulate AO of HD patients.

\section{Background}

Huntington disease (HD) is caused by expansion of a cytosine-adenine-guanine (CAG) trinucleotide repeat in the 5'-translated region of the IT15 gene on chromosome 4 , which encode the protein huntingtin [1]. The expansions result in the formation of elongated proteins with a variety of new properties. The extent of the expansion is inversely correlated with the age of onset (AO). Nevertheless, large part of the variance in $\mathrm{AO}$ remains unexplained
[2]. The pathogenesis of HD has been implicated to relate to different aspects of the homocysteine metabolism: Cystathionine [beta]-synthase (CBS) appears to bind specifically to huntingtin (htt) [3]. CBS deficiency is associated with homocystinuria, which affects various physiological systems, including the central nervous system. Homocysteine, one of the substrates of CBS accumulates in homocystinuria and is metabolized to homocysteate and homocysteine sulphinate, both components of which are 
Table I: Number of different genotype combinations of the MTHFR $677 \mathrm{C} \rightarrow T^{\mathrm{a}}$ and $1298 \mathrm{~A} \rightarrow \mathrm{C}^{b}$ polymorphism in $167 \mathrm{HD}$ patients

\begin{tabular}{llll}
\hline $\begin{array}{l}\text { MTHFR } \\
\text { genotype }\end{array}$ & $\begin{array}{l}\text { 677CC (\%) } \\
\mathbf{n = 7 1}\end{array}$ & $\begin{array}{l}\text { 677CT }(\%) \\
\mathbf{n}=75\end{array}$ & $\begin{array}{l}\text { 677TT (\%) } \\
\mathbf{n}=\mathbf{2 1}\end{array}$ \\
\hline I298AA $(\mathbf{n}=\mathbf{8 0})$ & $23(13.7)$ & $37(22.1)$ & $20(12)$ \\
I298AC $(\mathbf{n}=74)$ & $35(21)$ & $38(22.8)$ & $1(0.6)$ \\
I298CC $(\mathbf{n = 1 3 )}$ & $13(7.8)$ & 0 & 0
\end{tabular}

aAllele frequency of MTHFR 677T amounts to 0.35 .

bAllele frequency of MTHFR I298C amounts to 0.29.

amino acids with significant excitotoxic potential. In this context homocysteine was suggested to influence the pathogenesis of HD. Two common polymorphisms have been described in the MTHFR gene, both single nucleotide substitutions resulting in amino acid changes $($ C677T $\rightarrow$ Ala222Val and A1298C $\rightarrow$ Glu429Ala) $[4,5]$. Whereas C677T unequivocally affects enzyme function and has been associated with increased plasma homocysteine concentrations and an altered balance of folate metabolites [4], the functional relevance in vivo of the A1298C allele is less well defined. A1298C affects enzyme function in vitro to a lesser degree, and individuals carrying the variation have frequently normal homocysteine and plasma folate concentrations [6,7]. It is unclear whether the substitution affects folate metabolism under specific physiological conditions, e.g. under low nutrient intake. Apparently, the $677 \mathrm{C} \rightarrow \mathrm{T}$ and the $1298 \mathrm{~A} \rightarrow \mathrm{C}$ polymorphisms can act synergistically, given that heterozygosity for both polymorphisms causes lower MTHFR enzymatic activity than heterozygosity alone for either of them and a trend to higher or significantly higher plasma total homocysteine levels [8].

Brune et al. reported recently an association between the homozygous A1298C allele and a distinctly lower AO compared to the wild type MTHFR genotypes [9]. In the present study we re-examined the $1298 \mathrm{~A} \rightarrow \mathrm{C}$ polymorphism as well as its potential interaction with the $677 \mathrm{C} \rightarrow \mathrm{T}$ polymorphism as genetic factors influencing the $\mathrm{AO}$ of HD. Compared to the patient cohort examined by
Brune et al. $(\mathrm{n}=171)$, here 27 patients have been excluded from the initial cohort due to relatedness (the first diagnosed family member remained in this study) and lacking information on the motor age at onset. In contrast to the initial cohort, exclusively the motor AO was referred to. The present cohort $(n=167)$ has been supplemented by 23 patients due to recruitment of new patients. The potential influence of certain genotypes on $\mathrm{AO}$ was calculated by linear regression, in which $\mathrm{R}^{2}$ illustrates the relative improvement of the regression model when the various genotypes are considered in addition to the HD CAG repeats.

\section{Results and discussion}

Analysis of the MTHFR $677 \mathrm{C} \rightarrow \mathrm{T}$ and the $1298 \mathrm{~A} \rightarrow \mathrm{C}$ polymorphisms in 167 patients revealed allele frequencies of 0.35 for MTHFR 677T and 0.29 for MTHFR 1298C, respectively. Observed frequencies were in Hardy-Weinberg equilibrium.

The prevalences of the combined MTHFR genotypes for patients and controls are listed in Table 1. 23.3\% of the subjects represented combined heterozygotes for the two SNPs (1298AC/677CT). We found no double homozygous individuals (1298CC/677TT) and no patient carrying the $1298 \mathrm{CC} / 677 \mathrm{CT}$ genotype, a result to be expected based on genotype frequencies reported in other populations $[11,12]$. Thus our findings comply with the suspicion that these two polymorphisms occur rarely in cis [7]. Addition of the MTHFR genotype variations, alone and in combination (data only shown for the dominant model of the rare allele or the model for compound heterozygosity, respectively) to the effect of CAG repeat lengths resulted in no significant increase in the $\mathrm{R}^{2}$ value (Table 2). Hence, this study failed to replicate the association finding between the genotypes of the A1298C polymorphism in MTHFR with the AO of HD. Since our cohort comprises mostly the same individuals as investigated before (144/167), the initial description of association is due to weaker exclusion criteria concerning relatedness of patients as well as exclusive reference to motor AO. In addition different statistical principles were employed.

Table 2: Linear regression analysis concerning polymorphisms in the MTHFR gene

\begin{tabular}{lllcc}
\hline Gene (polymorphism) & $\mathbf{R}^{2}$ & $\Delta \mathbf{R}^{\mathbf{2}}$ & \% additional explained variance & $\mathbf{P}$ value \\
\hline HD CAG & .308 & - & $<.0005$ \\
\hline HD CAG + MTHFR AI298C & .304 & .004 & - & .850 \\
HD CAG + MTHFR C677T & .305 & .003 & - & .590 \\
HD CAG + compound heterozygotes & .304 & .004 & .828 \\
\hline
\end{tabular}

Variance in age at onset for the CAG repeats is indicated as such as well as in combination with the different polymorphisms examined. $\mathrm{R}^{2}$ illustrates the relative improvement of the regression model when the various genotypes are considered in addition to the HD CAG repeats, $\triangle R^{2}$ values quantify these differences. $P$ values refer to $R^{2}$. 


\section{Conclusion}

We failed to replicate the association finding between the 1298CC genotype in the MTHFR gene and earlier AO in HD. In future studies in this context, also the folate levels of individual patients should be taken into account as well as environmental factors.

\section{Methods}

One hundred sixty-seven patients clinically diagnosed as suffering from HD were ascertained for their motor AO in the Huntington Center (HZ) NRW, Bochum (Germany) [10]. All patients gave informed consent for genotyping. The CAG repeat sizes and the MTHFR A1298C and C677T genotypes were determined as described before [9]. The dependence of the AO on CAG repeat number was determined by linear regression. Residuals from this model were verified, and there was no evidence of departure from normality and equality of variance assumptions. The possible genotypic effects of the two polymorphisms were assessed with multiple linear regressions, while allowing for the predictive effects of the CAG repeat size. We used the AO as dependent variable and the respective genotypes as independent variables. The CAG repeat number was considered as numerical variable. All of the other putatively modifying genotypes were considered as nominal variables by assigning the value " 0,1 " or " $0,1,2$ " according to the subject's number of variant alleles under a model of dominance or otherwise according to a model of generalized additive allelic effect. SPSS Ver.11.0 for Windows (SPSS Inc.) was used for all statistical analyses.

\section{Competing interests}

The author(s) declare that they have no competing interests.

\section{Authors' contributions}

WH and LA initiated the study; WH carried out the molecular genetic studies and drafted the manuscript. JA and CS had ascertained the clinical status of the patients. SW and JTE participated in the study design and finalized the analyses as well as several versions of the paper.

All authors read and approved the final version of the manuscript.

\section{References}

I. Huntington's Disease Collaborative Research Group: A novel gene containing a trinucleotide repeat that is expanded and unstable on Huntington's disease chromosomes. Cell 1993, 72:97I-983.

2. Kehoe P, Krawczak M, Harper PS, Owen MJ, Jones AL: Age of onset in Huntington disease: sex specific influence of apolipoprotein E genotype and normal CAG repeat length. J Med Genet 1999, 36:108-11।.

3. Boutell JM, Wood JD, Harper PS, Jones AL: Huntingtin interacts with cystathionine beta-synthase. Hum Mol Genet 1998, 3:37I-378

4. Frosst P, Blom HJ, Milos R, Goyette P, Sheppard CA, Matthews RG, Boers G], den Heijer M, Kluijtmans LA, van den Heuvel LP, Rozen R:
A candidate genetic risk factor for vascular disease: a common mutation in methylenetetrahydrofolate reductase. Nat Genet 1995, 10:1 II-II3.

5. Weisberg I, Tran P, Christensen B, Sibani S, Rozen R: A second genetic polymorphism in methylenetetrahydrofolate reductase (MTHFR) associated with decreased enzyme activity. Mol Genet Metab 1998, 64:169-172.

6. Yamada K, Chen Z, Rozen R, Matthews RG: Effects of common polymorphisms on the properties of recombinant human methylenetetrahydrofolate reductase. Proc Natl Acad Sci USA 200I, 98: I 4853-I4858.

7. Weisberg IS, Jacques PF, Selhub J, Bostom AG, Chen Z, Curtis Ellison $\mathrm{R}$, Eckfeldt JH, Rozen R: The I298A->C polymorphism in methylenetetrahydrofolate reductase (MTHFR): in vitro expression and association with homocysteine. Atherosclerosis 200I, 156:409-4I5.

8. van der Put NMJ, Gabreels F, Stevens EMB: A second common mutation in the methyelenetetrahydrofolate reductase gene: an additional risk factor for neural-tube defects? $\mathrm{Am} \mathrm{J}$ Hum Genet 1998, 62:1044-105I.

9. Brune N, Andrich J, Gencik M, Saft C, Müller T, Valentin S, Przuntek $\mathrm{H}$, Epplen JT: Methyltetrahydrofolate Reductase polymorphism influences onset of Huntington's disease. J Neural Transm Suppl 2004, 68:105-II0.

10. Arning L, Kraus PH, Valentin S, Saft C, Andrich J, Epplen JT: NR2A and NR2B receptor gene variations modify age at onset in Huntington disease. Neurogenetics 2005, 1:25-28.

1I. Hanson NQ, Aras O, Yang F, Tsai MY: C677T and AI298C polymorphisms of the methylenetetrahydrofolate reductase gene: incidence and effect of combined genotypes on plasma fasting and post-methionine load homocysteine in vascular disease. Clin Chem 200I, 47:66I-666.

12. Kolling K, Ndrepepa G, Koch W, Braun S, Mehilli J, Schomig A, Kastrati A: Methylenetetrahydrofolate reductase gene C677T and AI 298C polymorphisms, plasma homocysteine, folate, and vitamin $B \mid 2$ levels and the extent of coronary artery disease. Am J Cardiol 2004, 10:1201-1206.

\section{Publish with BioMed Central and every scientist can read your work free of charge}

"BioMed Central will be the most significant development for disseminating the results of biomedical research in our lifetime. "

Sir Paul Nurse, Cancer Research UK

Your research papers will be:

- available free of charge to the entire biomedical community

- peer reviewed and published immediately upon acceptance

- cited in PubMed and archived on PubMed Central

- yours - you keep the copyright

Submit your manuscript here:

http://www.biomedcentral.com/info/publishing_adv.asp
BioMedcentral 